\title{
Can cerebellar input calibrate collicular topographic maps?
}

\author{
John Porrill, Sean Anderson, Paul Dean \\ From Nineteenth Annual Computational Neuroscience Meeting: CNS*2010 \\ San Antonio, TX, USA. 24-30 July 2010
}

There is substantial evidence that the repeating cerebellar microcircuit implements an adaptive filter algorithm suitable for fine tuning a wide range of sensorimotor skills [1]. Although it is known that the multimodal map layer of superior colliculus receives a massive cerebellar input which directly influences collicular output cells [2], there has been little speculation as to the function of this influence. We suggest here that these cerebellar inputs play a role in calibrating the accuracy of collicular topographic maps.

The cerebellum is a plausible candidate for this role for a number of reasons. It is known to be crucial for accuracy of saccades generated by colliculus. It is also known that cerebellar lesions impair prism adaptation of eye movements. A recent imaging study [3] found direct evidence of cerebellar activation during prism adaptation and suggests that "the cerebellum is particularly involved in [establishing] a correct spatial mapping among visuomotor and sensorimotor coordinates systems”. A modeling study [3] of collicular visuomotor mapping concludes that the transformation occurs in brainstem with the cerebellum adjusting it for accuracy, stating that "... the importance of the cerebellum has been neglected in previous modeling studies".

Here we investigate whether the adaptive filter model of the cerebellar microcircuit which has been so successful in conventional sensorimotor contexts can be applied without change to the very different computational problem of calibrating a topographic map driving an orienting response. We propose a model in which (i) unimodal sensory topographic maps constitute a probabilistic representation of target position and that these maps are optimally combined to produce a multimodal map [4] whose peak activity drives the orienting response, (ii) cerebellar input can bias the position of

\footnotetext{
* Correspondence: j.porrill@sheffield.ac.uk

Department of Psychology, University of Sheffield, Sheffield, S10 2TN, UK
}

peak map activity (e.g. by a process such as attentional gain modulation [5]), (iii) the cerebellum receives the sensory information that generates the topographic maps on its mossy fibre inputs, and (iv) information about orienting errors caused by miscalibration is made available to the cerebellum on its climbing fibre inputs and drives cerebellar learning.

We demonstrate in simulation that this mechanism can successfully calibrate topographic maps and go on to investigate its computational properties. For example we investigate a fundamental calibration ambiguity in which sensory maps can be miscalibrated in such a way that their effects on the combined estimate cancel. We show that this ambiguity is resolved in a plausible way if error signals are gated whenever a sensor fails to observe the target; a similar gating process has been observed in some motor behaviors [6]. We also demonstrate that optimality of the cerebellar learning rule [7] ensures that Purkinje cell synapses carrying cross-talk between sensors are driven to silence, greatly reducing the need to hard-wire the connectivity of parallel fiber inputs to the cerebellar microzones.

Published: 20 July 2010

\section{References}

1. Dean P, Porrill J, Ekerot CF, Jorntell H: The cerebellar microcircuit as an adaptive filter: experimental and computational evidence. Nat Rev Neurosci 2009, 11(1):30-43.

2. Westby GWM, Collinson C, Dean P: Excitatory drive from deep cerebellar neurons to the superior colliculus in the rat: an electrophysiological mapping study. Eur J Neurosci 1993, 5:1378-1388.

3. Luaute J, Schwartz S, Rossetti Y, Spiridon M, Rode G, Boisson D, Vuilleumier P: Dynamic changes in brain activity during prism adaptation. J Neurosci 2009, 29(1):169-178.

4. Tabareau N, Bennequin D, Berthoz A, Slotine JJ, Girard B: Geometry of the superior colliculus mapping and efficient oculomotor computation. Biol Cybern 2007, 97(4):279-292.

5. Patton P, Belkacem-Boussaid K, Anastasio TJ: Multimodality in the superior colliculus: an information theoretic analysis. Brain Res Cogn Brain Res 2002, 14(1):10-19. 
6. Salinas $E$, Abbott LF: Invariant visual responses from attentional gain fields. J Neurophysiol 1997, 77(6):3267-3272.

7. Apps R: Movement-related gating of climbing fibre input to cerebellar cortical zones. Prog Neurobiol 1999, 57(5):537-562.

8. Porrill J, Dean P: Silent synapses, LTP and the indirect parallel-fibre pathway: computational consequences of optimal noise processing. PLoS Comput Biol 2008, 4(5):e1000085.

doi:10.1186/1471-2202-11-S1-P120

Cite this article as: Porrill et al: Can cerebellar input calibrate collicular topographic maps? BMC Neuroscience 2010 11(Suppl 1):P120.

Submit your next manuscript to BioMed Central and take full advantage of:

- Convenient online submission

- Thorough peer review

- No space constraints or color figure charges

- Immediate publication on acceptance

- Inclusion in PubMed, CAS, Scopus and Google Scholar

- Research which is freely available for redistribution

Submit your manuscript at www.biomedcentral.com/submit 